\title{
Sağlık Çalışanlarında Mobbing Algısı ve İş Doyumunun Belirlenmesi
}

\author{
Determining Mobbing Perceptions and Job Satisfaction among Healthcare \\ Professionals
}

\author{
Nurhayat KILIÇ', Havva TEL ${ }^{2}$
}

İletişim/ Correspondence: Nurhayat KILIÇ Adres/Adress: Artvin Çoruh Üniversitesi Sağlık Bilimleri Fakültesi ARTVİN Tel: 04662151063 Fax 04662151064 E-mail: nurhayatim36@hotmail.com

\section{$\ddot{O} Z$}

Amaç: Bu araştırma sağllk çalışanlarında mobbing algısı ve iş doyumunun belirlenmesi amacı ile tanımlayıcı olarak yapıldl.

Yöntem: Araşstırmaya 390 sağllk çalışanı alındı. Araştırma verileri kişisel bilgi formu, mobbing algı ölçeği ve minnesota iş doyumu ölçeği ile topland. Verilerin analizinde yüzdelik dağıllm, Varyans analizi ve Pearson Korelasyon analizi kullanildl.

Bulgular: Sağllk çalışanlarının \%57.5'inin mobbing davranışına maruz kaldı̆̆g, mobbinge maruz kalan hekimlerin $\% 32.8$ 'inin, ebelerin \% 56.3'ünün ve teknisyenlerin \% 41.1' 'inin bu durumda hiçbir şey yapmadı ğ l, hemşirelerin \%33.8'inin durumu arkadaşlarıyla paylaştığ belirlenmiştir. Sağlık çalıșanlarının \%92 si mobbing'in iş doyumunu olumsuz etkilediğini belirtmiştir. Sağllk çalışanlarında mobbing algısı ile iş doyumu arasında güçlü ilişski olduğu sağllk çallşanlarında iş doyumu arttıkça mobbing algısının azaldiğı saptanmıştır ( $r=-.40, p=0.00)$.

Sonuç: Sağllk çalışanlarının yarıdan fazlasının mobbing davranışına maruz kaldı̆̆̆ ve bu durumun iş doyumlarını olumsuz etkilediği görülmüştür.

Anahtar Kelimeler: Mobbing, iş doyumu, sağlık çalışanı, hemşire.

\section{ABSTRACT}

Aim: This study has been carried out as definitive to determine job satisfaction and mobbing perception of health care workers.

Method: Three hundred and ninety healthcare professionals were enrolled in the study. Study data were collected with a personal information form, mobbing perceptional scale, and the Minnesota Job Satisfaction Scale. In the analysis of the data, percentage distribution, the Mann-Whitney U, Kruskal Wallis Variance Analysis and Pearson's correlation analysis tests were used.

Results: It has been determined \%57.5 of health care workers are exposed to mobbing and $32.8 \%$ of physicians, of 41.1 $\%$ of the and technicians $56.3 \%$ of midwives who exposed to mobbing did not do anything in this case but only $33.8 \%$ of nurses shared this with their friends. \%92 of health care workers stated that mobbing affects job satisfaction negatively. It has been determined that there is a strong relationship between mobbing perception and job satisfaction of health care workers and job satisfaction has been found to decrease with increasing perception of mobbing $(r=-.40, p=0.00)$.

Conclusion: It has been stated that more than half of health care workers are exposed to mobbing and mobbing affects job satisfaction of health care workers negatively.

Keywords: Mobbing, job satisfaction, healthcare professional, nurse.

Horatio, European Psychiatric Nursing Congress'de poster bildiri olarak sunulmuştur (31 Ekim - 2 Kasım 2013, İstanbul/ Türkiye), Cumhuriyet Üniversitesi Sağllk Bilimleri Enstitüsü̈ Yüksek Lisans Tezi 2013, ${ }^{1}$ Arş. Gör. Artvin Çoruh Üniversitesi Sağllk Bilimleri Fakültesi, Hemşirelik Bölümü, Artvin/ TURKEY, ${ }^{2}$ Prof. Dr. Cumhuriyet Üniversitesi Sağllk Bilimleri Fakültesi, Hemşirelik Bölümü, Sivas/ TURKEY

Yazının gönderilme tarihi: 04.04.2016

Yazının basım için kabul tarihi: 02.01.2017

doi: 10.17672/fnhd.50979 


\section{GíRiş}

Çalışma ortamı bireyin yaşamını sürdürebilmesi ve toplumda belli bir rol sahibi olabilmesi için bireyin hayatında önemli bir yere sahiptir (Bostan ve Erbil 2004). Çalışma yaşamı bireyin motivasyonunu, üretkenliğini artırdığı gibi yaşanılan psikolojik baskılar da çalışanın kendisini olumsuz algılamasına, olumsuz iş davranışlarında bulunmasina ve olumsuz duygular hissetmesine neden olabilmektedir (Bostan ve Erbil 2004; Köse ve Uysal 2010). Çalışma yaşamında çalışanları olumsuz etkileyen durumlardan birisi de iş yerinde yaşanılan mobbing durumlarıdır. Leymann (1990) iş yerindeki mobbing'i; "bir veya birkaç kişi tarafindan diğer bir kişiye yönelik olarak düşmanca ve ahlak dışı yöntemlerle sistematik bir biçimde uygulanan psikolojik terör" olarak tanımlamıştır. Mobbing insanı psikolojik ve fiziksel olarak tükenmişliğe sürükleyen, yıpratan, korkutan bir taciz şekli ve oldukça yaygın bir işyeri travmasıdır (Yıldırım 2007).

Mobbing'in iş yaşamında yaygın olarak yaşandığı düşünülmekle birlikte genellikle dile getirilmediği görülmektedir. Mobbing çalışma yaşamında birçok insanın yaşadığı ama büyük bölümünün farkında olmadığı bir olgudur. Mobbing yolu ile bireyin saygınlığına, güvenirliğine, mesleki yeterliğine sistematik ve sürekli olarak ahlak dışı yaklaşımlarla saldırılmakta, bireyin performansı ve dayanma gücünü yok edilerek, işten ayrılması hedeflenmektedir (Tetik 2010; Yıldırım 2007). Mobbing yaşantısı bireyi, ailesini ve çalıştığı kurumu çok yönlü etkilemektedir. Mobbing sonucunda bireyin sosyal imajı zedelenmekte, çoğunlukla fiziksel veya ruhsal hastalıklar ortaya çıkmakta, iş kazaları, işten ayrılmalar hatta intiharlar görülmektedir (Tetik 2010; Yıldırım 2007). Mobbing yaşayan bireyin aile ilişkileri bozulmakta, eşler arasındaki ilişki, ebeveyn-çocuk ilişkisi ve çocukların psikolojik gelişimleri olumsuz etkilenmektedir (Gökçe 2006; Tinaz 2011). Kurumda ise güvensiz bir çalışma ortamı oluşmakta, çalışanlar arasında çalışma barışı bozulabilmekte, kişilerarası ilişkilerde sorunlara neden olabilmekte, çalışanların iş verimi ve iş doyumu olumsuz etkilenmekte, kuruma ve işe bağlılık azalmaktadır (Kocaoğlu 2007; Köse ve Uysal 2010; Tinaz 2011; Tigrel ve Kokalan 2009).
Her işyerinde ve her kuruluşta görülebilen mobbing'in çok yaygın bir biçimde yaşandığ 1 alanlardan biri de sağlık sektörüdür. Sağlık sektöründe mobbing ile ilgili yapılan çalışmalarda; Güney Afrika'da kamu ve özel hastanelerde çalışan 1044 sağlık çalışanın \%6070'inin (Steinman 2003), Portekiz'de sağlık sektöründe çalışanların \%51'inin (Ferrinho ve ark. 2003), Jamaica'da 832 sağlık çalışanın \%46'sının (Jackson ve Ashley 2005) mobbing yaşadığı saptanmıştır. Sağl1k ekibi üyeleri arasında hemşirelerin mobbing'e daha fazla maruz kaldıkları belirtilmektedir. Yıldırım ve Yıldırım (2007) Kamu hastanesi (325) ile özel hastanede (180) çalışan 505 hemşirenin \%86.5'inin son bir yılda iş yerinde mobbing davranışı ile karşılaştığını, Karcıŏglu ve Akbaş (2010) kamu hastanesinde çalışan 210 hemşirenin \%38.6'sinin mobbing mağduru olduğunu belirlemiştir. Sağlık sektöründe görülen mobbing sağlık personelinin iş performansını, iş doyumunu, sosyal ilişkilerini, ruh sağlığını olumsuz yönde etkilemektedir (Dikmetaş, Top ve Ergin 2011; Jelic, Stoini ve Bunikic 2005). Bununla birlikte, sağlık hizmetleri birçok farklı meslek grubundan oluşan sağlık ekibi ile 24 saat kesintisiz olarak sürdürüldüğünden, sağlık ekibi üyelerinin işbirliği içinde çalışmas1, etkin ve kaliteli bir hizmet verilebilmesi için çalışanlarda motivasyonun sürdürülmesi, iş doyumunun ve memnuniyetinin sağlanması önemlidir. İş doyumu yüksek olan sağlık çalışanlarının yüksek kaliteli hizmet verdikleri, başarılı oldukları ve kuruma bağl11ıklarının yüksek olduğu bilinmektedir (Kuzey 2012; Topal 2008). Bu bağlamda sağlık çalışanlarının meslek gruplarına göre mobbing algısı ve iş doyumunun değerlendirilmesi, sağlık çalışanlarına mobbing'i tanıma, bu duruma karşı kendini koruma ve olumsuz etkilerini azaltma firsatı verecektir.

$\mathrm{Bu}$ araştırma Kars ili merkezindeki sağlık kurumlarında çalışan sağlık çalışanlarında mobbing algısı ve iş doyumunu belirlemek amacı ile yapılmıştır.

\section{YÖNTEM}

\section{Araştırmanın Tipi}

Araştırma tanımlayıcı tiptedir. 


\section{Araştırmanın Evreni ve Örneklemi}

Araştırmanın evrenini Kars ili merkezindeki sağlık kurum ve kuruluşlarında çalışan 790 sağlık personeli oluşturmuştur. Araştırmada örneklem seçimine gidilmemiştir. Ancak 230 sağlık çalışanı çalışmaya katılmayı kabul etmediği, 150 sağlık çalışanı bir yıldan az çalışma deneyimi olduğu, 20 sağlık çalışan veri araçlarını eksik doldurduğu için araştırmaya alınmamıştır. Araştırmanın örneklem grubunu ise Kars ili merkezindeki sağlık kurumlarında 1 Mart 2012 - 30 Haziran 2012 tarihleri arasında çalışan, en az 1 yıllık çalışma deneyimi olan ve çalışmaya katılmayı kabul eden, toplam 390 sağlık çalışanı oluşturmuştur. Araştırma örneklemi evrenin \%60.93’ünü temsil etmiştir.

\section{Veri Toplama Araçları ve Verilerin Toplanması}

Kişisel Bilgi Formu: Araştırmacı tarafından literatür taranarak oluşturulan bu form sağlık çalışanlarının cinsiyet, medeni durum, yaş, eğitim durumu, meslek, çalışma şekli, aynı kurumdaki çalışma süresi, toplam hizmet süresi, çalıştı̆̆ kurum, pozisyon, gelir düzeyi gibi demografik özellikleri belirlemeye yönelik 15 kapalı uçlu sorulardan oluşmaktadır (Aydın 2008; Dilman 2007; Fışkın 2011; Üye 2009; Zonp 2012).

Mobbing Algı Ölçeği: Ölçek Heinz Leymann tarafindan mobbing tipoloji olarak geliştirilmiştir (Leymann 1996). Mobbing tipolojisi Türkçeye Osman Cem Önertoy (2003) tarafından "Mobbing: İşyerinde Duygusal Taciz” (Davenport ve ark. 2003) adlı kitapta yayınlanarak kazandırılmıştır. Ölçek 5'li likert tipi 41 maddeden oluşmaktadır.. Ölçek 5'li likert tipi 41 maddeden oluşmaktadır. Ölçeğin alt grupları; kendini gösterme ve iletişim olanaklarının kısıtlanması $(1,2,3,4$, $5,6,7,8,9,10,11)$, sosyal ilişkilere saldırılar $(12,13$, $14,15,16)$, sosyal itibara saldırılar $(17,18,19,20,21$, $22,23,24,25,26,27,28)$, yaşam kalitesi ve mesleki duruma saldirilar $(29,30,31,32,33,34,35,36,37)$, sağlığa doğrudan saldırılara yönelik $(38,39,40,41)$ olarak sıralanmıştır. Ölçekten alınacak puanlar 41-205 arasında değişmektedir (Aydın 2008).
Minnesota İs Doyum Ölçeği: Ölçek Weiss, Dawis, England ve Lofquist (1967) tarafından geliştirilmiştir. Ölçeğin ülkemizde geçerlilik ve güvenilirlik çalışmas1 Oran-Başkaya (1989) tarafindan yapılmıştır. Ölçek 5'li likert tipi 20 maddeden oluşmaktadır. Ölçek maddeleri içsel doyum $(1,2,3,4,7,8,9,10,11,15$, $16,20)$ ve dişsal doyum $(5,6,12,13,14,17,18,19)$ olarak gruplandırılmaktadır (Tözün, Çulhacı ve Ünsal 2008; Yelboğa 2007). Ölçekten alınacak puanlar 20100 arasında değişmektedir. Puanların 20'ye yaklaşması doyum düzeyinin düştüğünü, 100'e yaklaşması ise yükseldiğini göstermektedir (Okyay 2009).

\section{Araştırmanın Etik Yönü}

Araştırma için Cumhuriyet Üniversitesi Araştırma ve Uygulama Hastanesi Etik Kurulu'ndan 15.02.2012 tarih ve 2012-02/14 no'lu kararla etik kurul izini alınmıştır. Kars il Sağlık Müdürlüğü ve Kafkas Üniversitesi Araştırma ve Uygulama Hastanesi'nden de kurum izinleri alınmıştır. Çalışmaya katılmak gönüllülük esasına dayandığından sağlık çalışanlarına konu hakkında sözlü ve yazılı olarak bilgi verilerek yazılı bilgilendirilmiş onam alınmıştır. Araştırma verileri Kişisel Bilgi Formu, Mobbing Algısı Ölçeği ve Minnesote İş Doyumu Ölçeği kullanılarak toplanmıştır. Veri toplama araçları çalışanlara kapalı zarflar içerisinde verilmiş, sağlık çalışanlarından veri toplama araçlarını 24 saat içerisinde, çalışma saatleri dışında doldurmaları istenmiş ve 24 saat sonra kapalı zarflarda geri alınmıştır.

\section{Verilerin Değerlendirilmesi}

Araştırma verileri SPSS 18.0 programda değerlendirilmiştir. Verilerin analizinde yüzdelik dağılım, Varyans Analizi (ANOVA) ve Pearson Correlation analizi testleri kullanılmış, yanılma düzeyi 0.05 olarak alınmıştır.

\section{BULGULAR}

Sağlık çalışanlarında mobbing algısı ve iş doyumunu belirlemek amacı ile yapılan bu araştırmaya 117 hekim, 116 hemşire, 83 ebe, 25 teknisyen, 49 diğer sağlık çalışanı (eczacı, psikolog, fizyoterapist, diyetisyen, sağlık memuru, sosyal hizmet uzmanı) katılmıştır. 
Tablo 1. Sağlık Çalışanlarının Demografik Özellikleri

\begin{tabular}{|c|c|c|c|c|c|c|c|c|c|c|c|}
\hline \multirow[b]{2}{*}{ Gruplar } & \multicolumn{2}{|c|}{$\begin{array}{c}\text { Hekim } \\
\text { (117) }\end{array}$} & \multicolumn{2}{|c|}{$\begin{array}{c}\text { Hemşire } \\
\text { (116) }\end{array}$} & \multicolumn{2}{|c|}{$\begin{array}{l}\text { Ebe } \\
(\mathbf{8 3})\end{array}$} & \multicolumn{2}{|c|}{$\begin{array}{l}\text { Teknisyen } \\
\text { (25) }\end{array}$} & \multicolumn{2}{|c|}{$\begin{array}{c}\text { Diğger Sağlık } \\
\text { Çalışanı } \\
(49)\end{array}$} & \multirow{2}{*}{$\begin{array}{c}\text { Toplam } \\
\text { (390) } \\
\text { Sayı \% }\end{array}$} \\
\hline & Sayı & $\%$ & Sayı & $\%$ & Sayı & $\%$ & Sayı & $\%$ & Sayı & $\%$ & \\
\hline \multicolumn{12}{|l|}{ Cinsiyet } \\
\hline Kadın & 41 & 35.0 & 109 & 94.0 & 83 & 100.0 & 12 & 48.0 & 31 & 63.3 & 27670.7 \\
\hline Erkek & 76 & 65.0 & 7 & 6.0 & $\ldots$. & $\ldots \ldots$ & 13 & 52.0 & 18 & 36.7 & 11429.3 \\
\hline \multicolumn{12}{|l|}{ Yaş } \\
\hline 21-30 Yaş & 45 & 38.5 & 63 & 54.3 & 31 & 37.3 & 7 & 28.0 & 43 & 87.8 & 18948.4 \\
\hline 31-40 Yaş & 72 & 61.5 & 41 & 35.4 & 33 & 39.8 & 12 & 48.0 & 6 & 12.2 & 16442.0 \\
\hline 41-50 Yaş & $\ldots .$. & $\ldots .$. & 12 & 10.3 & 19 & 22.9 & 6 & 24.0 & $\ldots$. & $\ldots .$. & $37 \quad 9.6$ \\
\hline \multicolumn{12}{|l|}{ Medeni Durumu } \\
\hline Evli & 61 & 52.1 & 66 & 56.9 & 54 & 65.1 & 20 & 80.0 & 17 & 34.7 & 21855.9 \\
\hline Bekar & 56 & 47.9 & 50 & 43.1 & 29 & 34.9 & 5 & 20.0 & 32 & 65.3 & 17244.1 \\
\hline \multicolumn{12}{|l|}{ Eğitim Durumu } \\
\hline Lise & $\ldots$ & $\ldots$ & 23 & 19.8 & 30 & 36.1 & 3 & 12.0 & 11 & 22.4 & $\begin{array}{ll}67 & 17.1 \\
\end{array}$ \\
\hline Ön Lisans & $\ldots \ldots$ & $\ldots$ & 30 & 25.8 & 42 & 50.6 & 18 & 72.0 & 16 & 32.7 & 10627.4 \\
\hline Lisans & $\ldots \ldots$ & $\ldots \ldots$ & 54 & 46.6 & 11 & 13.3 & 4 & 16.0 & 15 & 30.6 & $84 \quad 21.5$ \\
\hline Yüksek Lisans & 54 & 46.2 & 9 & 7.8 & $\ldots$ & $\ldots$ & $\ldots$ & $\ldots$ & 7 & 14.3 & $70 \quad 17.9$ \\
\hline Doktora & 63 & 53.8 & $\ldots$ & $\ldots$ & $\ldots$ & $\ldots$ & $\ldots$ & $\ldots$ & $\ldots$ & $\ldots$ & $\begin{array}{ll}63 & 16.1\end{array}$ \\
\hline \multicolumn{12}{|l|}{ Çalışma Şekli } \\
\hline Nöbet (24 st) & 7 & 6.0 & 51 & 44.0 & 12 & 14.5 & 4 & 16.0 & 15 & 30.6 & $89 \quad 22.8$ \\
\hline $8-16 \mathrm{st}$ & 46 & 39.3 & 44 & 37.9 & 38 & 45.8 & 2 & 8.0 & 18 & 36.7 & $148 \quad 37.9$ \\
\hline Vardiya Usulü & 9 & 7.7 & 17 & 14.7 & 33 & 39.7 & 15 & 60.0 & 16 & 32.7 & $90 \quad 23.1$ \\
\hline Diğer & 55 & 47.0 & 4 & 3.4 & $\ldots$ & $\ldots$ & 4 & 16.0 & $\ldots$ & $\ldots$ & $\begin{array}{ll}63 & 16.2 \\
\end{array}$ \\
\hline \multicolumn{12}{|l|}{ Çalışılan Kurum } \\
\hline Devlet Hastanesi & 53 & 45.3 & 81 & 69.8 & 55 & 66.3 & 18 & 72.0 & 12 & 24.5 & 21956.2 \\
\hline Üniversite Hastanesi & 41 & 35.1 & 35 & 30.2 & 3 & 3.6 & 5 & 20.0 & 25 & 51.0 & 10927.9 \\
\hline $\begin{array}{l}\text { Ağız ve Diş Sağlığı } \\
\text { Hastanesi }\end{array}$ & $\cdots$ & $\cdots$ & $\cdots$ & $\cdots$ & $\cdots$ & $\ldots$ & 2 & 8.0 & 12 & 24.5 & $14 \quad 3.6$ \\
\hline $\begin{array}{l}\text { Aile Sağlığı } \\
\text { Merkezi }\end{array}$ & 23 & 19.6 & $\cdots$ & $\cdots$ & 25 & 30.1 & $\cdots$ & $\cdots$ & $\cdots$ & $\cdots$ & $48 \quad 12.3$ \\
\hline \multicolumn{12}{|l|}{ Çalışma Süresi } \\
\hline $1-5$ Y1l & 54 & 46.2 & 51 & 44.0 & 17 & 20.5 & $\ldots$ & $\ldots$ & 40 & 81.6 & 16241.5 \\
\hline 6-10 Y11 & 45 & 38.4 & 24 & 20.6 & 17 & 20.5 & 16 & 64.0 & 9 & 18.4 & $111 \quad 28.5$ \\
\hline $11-15$ Y1l & 12 & 10.3 & 14 & 12.1 & 24 & 28.7 & 9 & 36.0 & $\ldots$ & $\ldots$ & $\begin{array}{ll}59 & 15.1 \\
\end{array}$ \\
\hline 16-20 Y1l & 6 & 5.1 & 16 & 13.8 & 13 & 15.7 & $\ldots$ & $\ldots$ & $\ldots \ldots$ & $\ldots \ldots$ & $35 \quad 9.0$ \\
\hline 21-30 Y11 & $\ldots$ & $\ldots$ & 11 & 9.5 & 12 & 14.5 & $\ldots \ldots$ & $\ldots .$. & $\ldots \ldots$ & $\ldots$ & $23 \quad 5.9$ \\
\hline \multicolumn{12}{|c|}{ Kurumdaki Çalışma Süresi } \\
\hline $1-5$ Y1l & 100 & 85.5 & 89 & 76.7 & 43 & 51.8 & 13 & 52.0 & 44 & 89.8 & 28974.1 \\
\hline 6-10 Y1l & 17 & 14.5 & 11 & 9.5 & 21 & 25.3 & 6 & 24.0 & 5 & 10.2 & $60 \quad 15.4$ \\
\hline $11-15 Y_{11}$ & $\ldots$ & $\ldots$ & 9 & 7.8 & 19 & 22.9 & 6 & 24.0 & $\ldots$ & $\ldots$ & 34 \\
\hline $16-20 Y_{11}$ & $\ldots$ & $\ldots$ & 7 & 6.0 & $\ldots$ & $\ldots$ & $\ldots$ & $\ldots$ & $\ldots$ & $\ldots$ & 1.8 \\
\hline
\end{tabular}

Tablo 1'de sağlık çalışanlarının demografik özellikleri görülmektedir. Araştırmaya katılan hekimlerin \%65.0'inin erkek, \%61.5'inin 31-40 yaş grubunda, \%52.1'inin evli, \%53.8'inin uzman doktor, \%47.0' sinin diğer çalışma saatleri arasında çalıştığ 1 , \%45.3'ünün devlet hastanesinde çalıştığ,$\% 46.2$ 'sinin 1-5 yıl arasında çalıştığ $1, \% 85.5$ 'inin aynı kurumda 1-5 yıl arasında çalıştığı saptanmıştır. 
Hemșirelerin \%94.0'ünün kadın, \%54.3'ünün 2130 yaş grubunda, \%56.9'unun evli, \%46.6'sinın lisans mezunu, \%44.0'ünün nöbet usulü ile çalıştığı, \%69.8'inin devlet hastanesinde çalıştığı, \%44.0'ünün 1-5 yıl arasında mesleki deneyime sahip olduğu, \%76.7'sinin aynı kurumda 1-5 yıl arasında çalıştığı belirlenmiştir.

Ebelerin tamamının kadın, \%39.8'inin 31-40 yaş grubunda, \%65.1'inin evli, \%50.6'sinın önlisans mezunu, \%45.8'inin 08-16 saatleri arası çalıştığ1, \%66.3'ünün devlet hastanesinde çalıştığ 1 , \%28.7'sinin 11-15 yıl arasında mesleki deneyime sahip olduğu, \%51.8'inin aynı kurumda 1-5 yıl arasında çalıştığı saptanmıştır.

Teknisyenlerin \%52.0'sinin erkek, \%48.0'ının 3140 yaş grubunda, \%80.0'inin evli, \%72.0'ının önlisans mezunu, \%60.0'ının vardiya usulü ile çalıştığ 1 , \%72.0'inin devlet hastanesinde çalıştı̆̆1, \%64.0'ünün 6-10 yıl arasında mesleki deneyime sahip olduğu, \%52.0'inin aynı kurumda 6-10 yıl arasında çalıştığı belirlenmiştir.
Araştırmaya katılan diğer sağlık çalışanlarının \%63.0'ünün kadın, \%87.8'inin 21-30 yaş grubunda, \%65.3'ünün bekar, \%32.7'sinin önlisans mezunu, \%36.7'sinin 08-16 saatleri arası çalıştı̆̆ , \%51.0'inin üniversite hastanesinde çalıştığ arasında mesleki deneyime sahip olduğu, \%89.8'inin aynı kurumda 1-5 yıl arasında çalıştığı saptanmıştır.

Tablo 2'de belirtildiği gibi hekimlerin \%62.4'ü, hemşirelerin \%53.4'ü, ebelerin \%49.4'ü, teknisyenlerin \%68.0'i, diğer sağlık çalışanlarının \%63.3'ü mobbing davranışına maruz kaldığı görülmektedir.

Sağlık çalışanlarının mobbing alg1 ölçeği puanları arasında istatistiksel olarak anlamlı bir fark olduğu belirlenmiştir $(\mathrm{p}<0.05)$. Araştırmada diğer sağlık çal1şanının kendini gösterme ve iletişim olanaklarının k1sitlanması puanı ile sosyal itibara saldırı puanı hekim, hemşire, ebe ve teknisyen puanından daha düşük, teknisyenlerin sağlığa doğrudan saldırı puanı ise hekim, hemşire, ebe ve diğer sağlık çalışanı puanından daha düşük saptanmıştır.

Tablo 2. Sağlık Çalışanlarının Mobbinge Maruz Kalma Durumu (n=224)

\begin{tabular}{|c|c|c|c|c|c|c|}
\hline $\begin{array}{l}\text { Mobbinge Maruz } \\
\text { Kalma Durumu }\end{array}$ & $\begin{array}{c}\text { Hekim } \\
\text { Sayı \% }\end{array}$ & $\begin{array}{l}\text { Hemşire } \\
\text { Sayı \% }\end{array}$ & $\begin{array}{c}\text { Ebe } \\
\text { Sayı \% }\end{array}$ & $\begin{array}{c}\text { Teknisyen } \\
\text { Sayı \% }\end{array}$ & $\begin{array}{c}\text { Diğer Sağlık } \\
\text { Çalışanı } \\
\text { Sayı \% }\end{array}$ & $\begin{array}{l}\text { Toplam } \\
\text { Sayı \% }\end{array}$ \\
\hline $\begin{array}{l}\text { Kalan } \\
\text { Kalmayan }\end{array}$ & $\begin{array}{ll}73 & 62.4 \\
44 & 37.6\end{array}$ & $\begin{array}{ll}62 & 53.4 \\
54 & 46.6\end{array}$ & $\begin{array}{ll}41 & 49.4 \\
42 & 50.6\end{array}$ & $\begin{array}{cc}17 & 68.0 \\
8 & 32.0\end{array}$ & $\begin{array}{ll}31 & 63.3 \\
18 & 36.7\end{array}$ & $\begin{array}{ll}224 & 57.5 \\
166 & 42.5\end{array}$ \\
\hline
\end{tabular}

Tablo 3. Sağlık Çalışanlarının Mobbing Algı Ölçeği Puanları

\begin{tabular}{|c|c|c|c|c|c|}
\hline \multirow[b]{2}{*}{ Sağlık Çalışanı } & \multicolumn{5}{|c|}{ Mobbing Algı Ölçeği Puanları } \\
\hline & $\begin{array}{c}\text { Kendini Gösterme } \\
\text { ve İletişim Olanaklarının } \\
\text { Kısıtlanması } \\
\text { X } \pm \text { SD }\end{array}$ & $\begin{array}{c}\text { Sosyal } \\
\text { İlişkilere Saldırı } \\
\text { X } \pm \text { SD }\end{array}$ & $\begin{array}{c}\text { Sosyal İtibara } \\
\text { Saldırı } \\
\text { X } \pm \text { SD }\end{array}$ & $\begin{array}{c}\text { Yaşam Kalitesi ve } \\
\text { Mesleki Duruma } \\
\text { Saldırı } \\
\text { X } \pm \text { SD }\end{array}$ & $\begin{array}{l}\text { Sağlığa } \\
\text { Doğrudan } \\
\text { Saldırı } \\
\text { X } \pm \text { SD }\end{array}$ \\
\hline Hekim & $22.27 \pm 7.86$ & $5.68 \pm 2.26$ & $14.60 \pm 5.25$ & $10.84 \pm 4.78$ & $4.79 \pm 2.41$ \\
\hline Hemşire & $19.86 \pm 7.31$ & $6.11 \pm 2.19$ & $15.70 \pm 5.66$ & $12.53 \pm 5.79$ & $4.93 \pm 2.02$ \\
\hline Ebe & $19.76 \pm 7.38$ & $5.72 \pm 2.55$ & $13.96 \pm 4.54$ & $10.40 \pm 3.95$ & $4.47 \pm 1.76$ \\
\hline $\begin{array}{l}\text { Diğer } \\
\text { Sağlık } \\
\text { Çalışanı }\end{array}$ & $19.18 \pm 6.38$ & $5.86 \pm 1.51$ & $16.51 \pm 5.80$ & $11.65 \pm 5.34$ & $4.59 \pm 1.35$ \\
\hline Teknisyen & $22.80 \pm 6.45$ & $5.44 \pm 0.87$ & $15.80 \pm 6.12$ & $11.56 \pm 5.23$ & $4.12 \pm 0.33$ \\
\hline $\mathbf{F} ; \mathbf{p}$ & $\mathrm{F}=3.10 ; \mathbf{p}=\mathbf{0 . 0 2}$ & $\mathrm{F}=0.88 ; \mathrm{p}=0.48$ & $\mathrm{~F}=2.50 ; \mathrm{p}=\mathbf{0 . 0 4}$ & $\mathrm{F}=2.68 ; \mathbf{p}=\mathbf{0 . 0 3}$ & $\mathrm{F}=1.34 ; \mathrm{p}=0.26$ \\
\hline
\end{tabular}


Tablo 4. Sağlık Çalışanlarının Mobbing Durumuna Yaklaşımı $(n=224)$

\begin{tabular}{|c|c|c|c|c|c|c|}
\hline Mobbing Durumunda Yaklaşım & $\begin{array}{l}\text { Hekim } \\
\text { n } \%\end{array}$ & $\begin{array}{c}\text { Hemşire } \\
\text { n } \%\end{array}$ & $\begin{array}{c}\text { Ebe } \\
\text { n } \%\end{array}$ & $\begin{array}{c}\text { Teknisyen } \\
\text { n } \% \\
\end{array}$ & $\begin{array}{c}\text { Diğer Sağlık Çalışanı } \\
\text { n } \%\end{array}$ & $\begin{array}{c}\text { Toplam } \\
\text { n } \%\end{array}$ \\
\hline Hiçbir şey yapmamak & 2432.8 & 1219.3 & 2356.3 & $7 \quad 41.1$ & $\begin{array}{ll}6 & 19.3\end{array}$ & 7232.1 \\
\hline Durumu arkadaşı ile paylaşmak & 2230.1 & 2133.8 & $8 \quad 19.5$ & $4 \quad 23.5$ & $5 \quad 16.1$ & 6026.7 \\
\hline Sorun yaşadığı kişi ile konuşmak & $6 \quad 8.1$ & 1219.3 & $\begin{array}{ll}5 & 12.1\end{array}$ & $6 \quad 35.4$ & $9 \quad 29.2$ & $38 \quad 17.0$ \\
\hline Yöneticiden yardım istemek & 2129.0 & $8 \quad 12.9$ & $\begin{array}{ll}5 & 12.1 \\
\end{array}$ & 0.0 & $\begin{array}{ll}5 & 16.1 \\
\end{array}$ & 3917.4 \\
\hline Yasal süreci araştırmak & $\begin{array}{ll}0 & 0.0\end{array}$ & $9 \quad 14.7$ & $\begin{array}{ll}0 & 0.0\end{array}$ & 0.0 & 19.3 & 156.8 \\
\hline
\end{tabular}

Sağlık çalışanlarının mobbing durumuna yaklaşımlarında; hekimlerin \%32.8'inin, ebelerin \%56.3'ünün ve teknisyenlerin \%41.1'inin hiçbir şey yapmadığı, hemşirelerin \%33.8'inin bu durumu arkadaşlarılyla paylaştıklarını, diğer sağlık çalışanlarının ise \%29.2'sinin durumu sorun yaşadıkları kişiler ile paylaştıkları belirlenmiştir.

Tablo 5. Sağlık Çalışanlarının İş Doyumu Ölçeği Puanları

\begin{tabular}{|c|c|c|c|}
\hline $\begin{array}{l}\text { Sağlık } \\
\text { Çalışanı }\end{array}$ & \multicolumn{3}{|c|}{ İş Doyumu } \\
\hline & $\begin{array}{c}\text { İçsel Doyum } \\
\text { X } \pm \text { SD }\end{array}$ & $\begin{array}{c}\text { Dişsal Doyum } \\
\text { X } \pm \text { SD }\end{array}$ & $\begin{array}{c}\text { Genel } \\
\text { Doyum } \\
\text { X } \pm \text { SD }\end{array}$ \\
\hline Hekim & $38.50 \pm 12.72$ & $23.21 \pm 8.65$ & $61.71 \pm 20.28$ \\
\hline Hemşire & $35.97 \pm 10.61$ & $20.82 \pm 7.52$ & $56.78 \pm 17.33$ \\
\hline Ebe & $39.23 \pm 10.75$ & $23.02 \pm 8.15$ & $62.25 \pm 18.13$ \\
\hline Teknisyen & $28.16 \pm 12.00$ & $17.44 \pm 7.67$ & $45.60 \pm 19.03$ \\
\hline $\begin{array}{l}\text { Diğer } \\
\text { Sağlık } \\
\text { Çalışanı }\end{array}$ & $39.45 \pm 9.67$ & $23.29 \pm 7.86$ & $62.73 \pm 16.66$ \\
\hline $\mathrm{F}, \mathrm{p}$ & $\begin{array}{l}F=38.50 \\
p=12.72\end{array}$ & $\begin{array}{c}F=23.21 \\
p=8.65\end{array}$ & $\begin{array}{l}F=61.71 \\
p=20.28\end{array}$ \\
\hline
\end{tabular}

Tablo 5'te sağlık çalışanlarının iş doyumu ölçeği puanları görülmektedir. Sağlık çalışanlarının iş doyumu puanları arasında istatistiksel olarak anlamlı fark olmadı ̆̆ 1 belirlenmiştir ( $>00.05)$.

Sağlık çalışanlarının mobbing algısı ile iş doyumları arasındaki ilişki değerlendirildiğinde; hekim ve hemşirelerde mobbing algısı ve iş doyumu arasında istatistiksel olarak negatif anlamlı zayıf bir ilişki, ebelerde mobbing algısının kendini gösterme ve iletişim ola- naklarının kısıtlanması boyutu ile iş doyumunun dışsal doyum boyutu arasinda istatistiksel olarak negatif anlamlı güçlü bir ilişki olduğu saptanmıştır. Teknisyenlerin mobbing algısının kendini gösterme ve iletişim olanaklarının kısıtlanması boyutu ile iş doyumunun tüm boyutları ile mobbing algısının sosyal ilişkilere saldırı boyutu ile iş doyumunun içsel doyum ve genel doyum arasında istatistiksel olarak negatif anlamlı güçlü bir ilişki olduğu, diğer sağlık çalışanlarında ise mobbing algısının sosyal itibara saldırı boyutu ile dışsal doyum arasında istatistiksel olarak negatif anlamlı güçlü bir ilişki olduğu saptanmıştır.

\section{TARTIŞMA}

Kars il merkezinde sağlık kurum ve kuruluşlarında çalışan sağlık personeli ile yapılan bu çalışmada sağlık çalışanlarının yarıdan fazlasının mobbing davranış1na maruz kaldığı saptanmıştır. Sağlık çalışanlarında mobbing'in araştırıldığ çalışmalarda; Quine (2001) sağlık çalışanlarının \%44'ünün mobbing'e maruz kaldığını, Fışkın (2011) ebe ve hemşirelerin \%64.7'sinin, hekimlerin \%52.9'unun, laborantların ve diğer sağlık personellerinin \%66.7'sinin en az bir defa mobbing davranışı ile karşılaştıklarını saptamıştır. Bu sonuçlar araştırma bulgusu ile benzerlik göstermektedir. Y1ldız, Yıldız ve Erdağı (2009) Kars’ta 167 sağlık personeli ile yaptıkları çalışmada sağlık çalışanlarının \%35.3'ünün yüksek düzeyde mobbing'e maruz kald1ğını saptamıştır.

Araştırmada mobbing'e maruz kalan sağlık çalışanlarının meslek gruplarına göre farklı yaklaşımlarda bulundukları, hekim, ebe ve teknisyenlerin mobbing duruma yönelik bir şey yapmama, hemşirelerin durumu 
Tablo 6. Sağlık Çalışanlarının Mobbing Algısı ile İş Doyumları Arasındaki İlişki

\begin{tabular}{|c|c|c|c|c|c|c|}
\hline & & Hekim & Hemşire & Ebe & Teknisyen & $\begin{array}{c}\text { Diğer Sağlık } \\
\text { Çalışanı } \\
\end{array}$ \\
\hline \multirow{3}{*}{$\begin{array}{l}\text { Kendini Gösterme ve } \\
\text { İletişim Olanaklarının } \\
\text { Kısıtlanması }\end{array}$} & İçsel doyum & $\begin{array}{l}\mathrm{r}=-0.16 \\
\mathrm{p}=0.08\end{array}$ & $\begin{array}{c}\mathrm{r}=-0.43 * * \\
\mathbf{p}=\mathbf{0 . 0 0}\end{array}$ & $\begin{array}{c}\mathrm{r}=-0.33 * * \\
\mathbf{p}=\mathbf{0 . 0 0}\end{array}$ & $\begin{array}{c}\mathrm{r}=-0.53 * * \\
\mathbf{p}=\mathbf{0 . 0 1}\end{array}$ & $\begin{array}{l}\mathrm{r}=-0.17 \\
\mathrm{p}=0.24\end{array}$ \\
\hline & Dişsal doyum & $\begin{array}{c}\mathrm{r}=-0.24 * * \\
\mathbf{p}=\mathbf{0 . 0 1}\end{array}$ & $\begin{array}{c}\mathrm{r}=-0.44^{* *} \\
\mathbf{p}=\mathbf{0 . 0 0}\end{array}$ & $\begin{array}{c}\mathrm{r}=-0.51^{* *} \\
\mathbf{p}=\mathbf{0 . 0 0}\end{array}$ & $\begin{array}{c}\mathrm{r}=-0.54 * * \\
\mathbf{p}=\mathbf{0 . 0 1}\end{array}$ & $\begin{array}{c}\mathrm{r}=-0.37 * * \\
\mathbf{p}=\mathbf{0 . 0 1}\end{array}$ \\
\hline & Genel doyum & $\begin{array}{c}r=-0.19^{*} \\
\mathbf{p}=\mathbf{0 . 0 4}\end{array}$ & $\begin{array}{c}\mathrm{r}=-0.45^{* *} \\
\mathbf{p}=\mathbf{0 . 0 0}\end{array}$ & $\begin{array}{c}\mathrm{r}=-0.43^{* *} \\
\mathbf{p}=\mathbf{0 . 0 0}\end{array}$ & $\begin{array}{c}\mathrm{r}=-0.52 * * \\
\mathbf{p}=\mathbf{0 . 0 1}\end{array}$ & $\begin{array}{l}\mathrm{r}=-0.28 \\
\mathrm{p}=0.05\end{array}$ \\
\hline \multirow{3}{*}{ Sosyal İlişkilere Saldırı } & İçsel doyum & $\mathrm{r}=-0.07 \mathrm{p}=0.43$ & $\begin{array}{l}\mathrm{r}=-0.11 \\
\mathrm{p}=0.22\end{array}$ & $\begin{array}{c}\mathrm{r}=-0.39 * * \\
\mathbf{p}=\mathbf{0 . 0 0}\end{array}$ & $\begin{array}{c}\mathrm{r}=0.63 * * \\
\mathbf{p}=\mathbf{0 . 0 0}\end{array}$ & $\begin{array}{l}\mathrm{r}=-0.28 \\
\mathrm{p}=0.06\end{array}$ \\
\hline & Dişsal doyum & $\mathrm{r}=-0.15 \mathrm{p}=0.11$ & $\begin{array}{l}\mathrm{r}=0.09 \\
\mathrm{p}=0.36\end{array}$ & $\begin{array}{c}\mathrm{r}=-0.36^{* *} \\
\mathbf{p}=\mathbf{0 . 0 0}\end{array}$ & $\begin{array}{c}\mathrm{r}=0.48^{*} \\
\mathbf{p}=\mathbf{0 . 0 2}\end{array}$ & $\begin{array}{c}\mathrm{r}=-0.38 * * \\
\mathbf{p}=\mathbf{0 . 0 1}\end{array}$ \\
\hline & Genel doyum & $\mathrm{r}=-0.12 \mathrm{p}=0.21$ & $\begin{array}{l}\mathrm{r}=-0.12 \\
\mathrm{p}=0.20\end{array}$ & $\begin{array}{c}\mathrm{r}=-0.38^{* *} \\
\mathbf{p}=\mathbf{0 . 0 0}\end{array}$ & $\begin{array}{c}\mathrm{r}=0.59 * * \\
\mathbf{p}=\mathbf{0 . 0 0}\end{array}$ & $\begin{array}{c}\mathrm{r}=-0.34^{*} \\
\mathbf{p}=\mathbf{0 . 0 2}\end{array}$ \\
\hline \multirow{3}{*}{ Sosyal İtibara Saldırı } & İçsel doyum & $\mathrm{r}=-0.14 \mathrm{p}=0.14$ & $\begin{array}{c}\mathrm{r}=-0.38 * * \\
\mathbf{p}=\mathbf{0 . 0 0}\end{array}$ & $\begin{array}{c}r=-0.23^{*} \\
\mathbf{p}=\mathbf{0 . 0 4}\end{array}$ & $\begin{array}{l}r=-0.01 \\
p=0.98\end{array}$ & $\begin{array}{c}\mathrm{r}=-0.43 * * \\
\mathbf{p}=\mathbf{0 . 0 0}\end{array}$ \\
\hline & Dişsal doyum & $\mathrm{r}=-0.16 \mathrm{p}=0.09$ & $\begin{array}{c}\mathrm{r}=-0.38^{* *} \\
\mathbf{p}=\mathbf{0 . 0 0}\end{array}$ & $\begin{array}{c}\mathrm{r}=-0.25^{*} \\
\mathbf{p}=\mathbf{0 . 0 2}\end{array}$ & $\begin{array}{l}\mathrm{r}=-0.10 \\
\mathrm{p}=0.65\end{array}$ & $\begin{array}{c}\mathrm{r}=-0.52 * * \\
\mathbf{p}=\mathbf{0 . 0 0}\end{array}$ \\
\hline & Genel doyum & $\mathrm{r}=-0.16 \mathrm{p}=0.08$ & $\begin{array}{c}\mathrm{r}=-0.40 * * \\
\mathbf{p}=\mathbf{0 . 0 0}\end{array}$ & $\begin{array}{c}\mathrm{r}=-0.25^{*} \\
\mathbf{p}=\mathbf{0 . 0 3}\end{array}$ & $\begin{array}{l}\mathrm{r}=-0.02 \\
\mathrm{p}=0.92\end{array}$ & $\begin{array}{c}\mathrm{r}=-0.49 * * \\
\mathbf{p}=\mathbf{0 . 0 0}\end{array}$ \\
\hline \multirow{3}{*}{$\begin{array}{l}\text { Yaşam Kalitesi ve } \\
\text { Mesleki Duruma Saldırı }\end{array}$} & İçsel doyum & $\begin{array}{c}\mathrm{r}=-0.19 * \\
\mathbf{p}=\mathbf{0 . 0 4}\end{array}$ & $\begin{array}{c}\mathrm{r}=-0.34 * * \\
\mathbf{p}=\mathbf{0 . 0 0}\end{array}$ & $\begin{array}{c}\mathrm{r}=-0.28^{* *} \\
\mathbf{p}=\mathbf{0 . 0 1}\end{array}$ & $\begin{array}{l}\mathrm{r}=0.06 \\
\mathrm{p}=0.77\end{array}$ & $\begin{array}{c}r=-0.29 * \\
\mathbf{p}=\mathbf{0 . 0 4}\end{array}$ \\
\hline & Dışsal doyum & $\begin{array}{l}\mathrm{r}=-0.17 \\
\mathrm{p}=0.06\end{array}$ & $\begin{array}{c}\mathrm{r}=-0.28^{* *} \\
\mathbf{p}=\mathbf{0 . 0 0}\end{array}$ & $\begin{array}{c}r=-0.24^{*} \\
\mathbf{p}=\mathbf{0 . 0 3}\end{array}$ & $\begin{array}{l}\mathrm{r}=-0.17 \\
\mathrm{p}=0.40\end{array}$ & $\begin{array}{c}\mathrm{r}=-0.37 * * \\
\mathbf{p}=\mathbf{0 . 0 1}\end{array}$ \\
\hline & Genel doyum & $\begin{array}{c}\mathrm{r}=-0.20^{*} \\
\mathbf{p}=\mathbf{0 . 0 3}\end{array}$ & $\begin{array}{c}\mathrm{r}=-0.34 * * \\
\mathbf{p}=\mathbf{0 . 0 0}\end{array}$ & $\begin{array}{c}\mathrm{r}=-0.28 * \\
\mathbf{p}=\mathbf{0 . 0 1}\end{array}$ & $\begin{array}{l}\mathrm{r}=0.01 \\
\mathrm{p}=0.98\end{array}$ & $\begin{array}{c}\mathrm{r}=-0.34^{*} \\
\mathbf{p}=\mathbf{0 . 0 2}\end{array}$ \\
\hline \multirow{3}{*}{ Sağlığa Doğrudan Saldırı } & İçsel doyum & $\begin{array}{c}\mathrm{r}=-0.19 * \\
\mathbf{p}=\mathbf{0 . 0 4}\end{array}$ & $\begin{array}{c}\mathrm{r}=-0.34 * * \\
\mathbf{p}=\mathbf{0 . 0 0}\end{array}$ & $\begin{array}{c}\mathrm{r}=-0.34 * * \\
\mathbf{p}=\mathbf{0 . 0 0}\end{array}$ & $\begin{array}{l}\mathrm{r}=-0.10 \\
\mathrm{p}=0.62\end{array}$ & $\begin{array}{c}\mathrm{r}=-0.32^{*} \\
\mathbf{p}=\mathbf{0 . 0 3}\end{array}$ \\
\hline & Dışsal doyum & $\begin{array}{r}\mathrm{r}=-0.12 \\
\mathrm{p}=0.21\end{array}$ & $\begin{array}{c}\mathrm{r}=-0.27 * * \\
\mathbf{p}=\mathbf{0 . 0 0}\end{array}$ & $\begin{array}{c}\mathrm{r}=-0.31 * * \\
\mathbf{p}=\mathbf{0 . 0 1}\end{array}$ & $\begin{array}{l}\mathrm{r}=-0.21 \\
\mathrm{p}=0.32\end{array}$ & $\begin{array}{c}\mathrm{r}=-0.40 * * \\
\mathbf{p}=\mathbf{0 . 0 1}\end{array}$ \\
\hline & Genel doyum & $\begin{array}{l}\mathrm{r}=-0.16 \\
\mathrm{p}=0.09\end{array}$ & $\begin{array}{c}\mathrm{r}=-0.32 * * \\
\mathbf{p}=\mathbf{0 . 0 0}\end{array}$ & $\begin{array}{c}\mathrm{r}=-0.34 * * \\
\mathbf{p}=\mathbf{0 . 0 0}\end{array}$ & $\begin{array}{l}\mathrm{r}=-0.10 \\
\mathrm{p}=0.62\end{array}$ & $\begin{array}{c}\mathrm{r}=-0.40 * * \\
\mathbf{p}=\mathbf{0 . 0 0}\end{array}$ \\
\hline
\end{tabular}

\section{$* \mathbf{p}<0.05$}

$* * \mathbf{p}<0.01$

diğer arkadaşları ile paylaşma, diğer sağlık çalışanlarının da durumu sorun yaşadıkları kişiler ile paylaşma gibi yaklaşımları daha fazla ortaya koydukları görülmüştür. Sağlık personelinin mobbing durumunda çoğunlukla hiç bir şey yapmaması sonucunda; mobbing davranışlarının günlük yaşamda normal davranış olarak algılanmasının, çalışma ortamında açık, etkin iletişimin olmamasının, sağlık personelinin gerek mesleki eğitiminde gerekse hizmet içi eğitimlerinde mobbing ile mücadele konusuna yeterince yer verilmemesinin etkili olduğu düşünülmektedir. Yapılan çalışmalarda sağlık çalışanlarının mobbing durumuna yaklaşımları oldukça farklılık göstermektedir. Bazı çalı̧̧malarda mobbing durumuna bireylerin; \%42'sinin sessiz kalma, \%30.6'sının davranışı yapan kişiyi görmezden gelme (Bardakçı 2014), \%94.4'ünün eleştiri almamak için işine daha çok özen gösterme (Fışkın 2011) şeklinde yaklaşımda bulunduğu, bazı çalışmalarda da bireylerin \%91.7'sinin mobbing durumunu sorun yaşadığ kişiyle yüz yüze konuşarak çözmeye çalışma, \%69.4'ünün durumu üst makama bildirme (Fışkın 2011), \%19.2'sinin eylemi yapana aynı şekilde 
karş1lık verme, \%19.7'sinin eylemi yapanı yazılı olarak şikayet etme (Tüfekçi 2014) şeklinde yaklaşımda bulundukları belirlenmiştir.

Çalışmada sağlık çalışanlarının iş doyumu düzeyinin birbirine yakın olduğu ve her bir sağlık meslek grubu çalışanının büyük çoğunluğunun mobbing durumunun iş doyumunu olumsuz etkilediğini belirttiği görülmüştür (Tablo 5 ve 6). Karcığlu ve Akbaş (2010) sağlık çalışanlarında psikolojik şiddet ile iş doyumu arasında negatif anlamlı bir ilişki olduğunu belirlemiştir. Mobbing iş doyumunun azalması ile birlikte iş veriminin düşmesine de neden olmaktadır. Sağlık çalışanları ile yapılan birçok çalışmada da mobbing' in iş doyumunu olumsuz etkilediği sonucuna ulaşılmıştır (Einarsen, Matthiesen ve Skogstad 1998; Vega ve Comer 2005; Yavuz 2007). Çalışma bulgusu araştırma sonuçları ile uyumludur.

Araştırmada hekim, hemşire ve ebelerin kendini gösterme ve iletişim olanaklarının kısıtlanması puanları, sosyal itibara saldırı ile sağlığa doğrudan saldırı puanlarını yüksek bulunmuştur (Tablo 3). Yapılan çalışmalarda da mobbing'e maruz kalan çalışanların kendini gösterme ve iletişim olanaklarının kısıtlanması puanları yüksek bulunmuştur (Çakıl 2011; Dündar 2010; Gürkan 2010). Yıldız, Akbolat ve Işık (2011) mobbing'e maruz kalan sağlık çalışanlarında kişinin kendini gösterme ve iletişim olanaklarına yönelik saldırı boyutu puanının hekimlerde daha yüksek olduğunu bunu teknisyen, diğer sağlı personeli ve hemşirelerin puanlarının izlediğini, Şahin ve Dündar (2011) ise mobbing'e maruz kalan sağlık çalışanlarının kendini gösterme ve iletişim olanaklarının kısıtlanması puanları ile sosyal itibara saldırı puanlarının yüksek olduğunu belirlemiştir. Bu bulgu araştırma sonuçları ile benzerlik göstermektedir.

Sağlık çalışanlarında mobbing algısı ile iş doyumu arasında anlamlı negatif ilişki olmakla birlikte bu ilişkinin gücünün hekim ve hemşirelerde zayıf, ebelerde ve teknisyenlerde güçlü olduğu bulunmuştur (Tablo 6). Mobbing'in çalışanın iş doyumunu olumsuz etkilediğgi, iş doyumunun düşmesine, kurum ikliminin olumsuz özellikler taşımasına neden olduğu belirtilmektedir (Hoel, Cooper ve Faragher 2001; Salin 2003). Özalp (2013) mobbing ile iş doyumu arasında anlamlı negatif yönlü ve güçlü bir ilişkinin olduğunu mobbing'in iş doyumunu azalttığını saptamıştır. Mobbing algısının kendini gösterme ve iletişim olanaklarının kısıtlanması düzeyi tüm sağlık çalışanlarının içsel doyum düzeyini azaltmaktadır. Sağlık çalışanlarında mobbing algısı ve iş doyumu ölçeği alt boyutu arasında herhangi bir çalışma sonucuna rastlanmamakla birlikte fark11 meslek gruplarında yapılan çalışmalarda kendisini göstermesi ve iletişim olanaklarının kısıtlanmasına yönelik yapılan saldırıların çalışanların iş doyumunu azalttığ 1 belirlenmiştir (Cengiz, Aytaç, Servi ve Yetiş 2012; Vural-Özkan 2011; Yapıc1 2008).

Sağlık çalışanlarının sürekli ve etkin hizmet vermesinde kendilerini güvende ve değerli hissettikleri bir kurum iklimi önemli bir yere sahiptir. Bu nedenle sağlık çalışanlarına mobbing'den uzak, iş doyumunu destekleyen ve iş doyumunu olumsuz etkileyecek faktörleri önleyen veya azaltan bir çalışma ortamının sağlanması ve sürdürülmesi gerekmektedir.

\section{SONUÇ VE ÖNERILER}

Kars ilinde kamu kurumlarında çalışan hekim, hemşire, ebe, teknisyen ve diğer sağlık çalışanlarında mobbing algısı ve iş doyumunun belirlenmesi amacı ile yapılan bu çalışmada sağlık çalışanlarının yarıdan fazlasının mobbing davranışına maruz kaldığı, sağlık çalışanlarının mobbing durumuna yaklaşımlarının farklılık gösterdiği hekim, ebe ve teknisyenlerin mobbing duruma yönelik birşey yapmama, hemşirelerin durumu diğer arkadaşları ile paylaşma, diğer sağlık çalışanlarının da durumu sorun yaşadıkları kişilerle paylaşma gibi yaklaşımları seçtikleri, mobbing yaşantısının sağlık çalışanlarının iş doyumunu olumsuz etkilediği belirlenmiştir. Araştırmada elde edilen sonuçlar doğrultusunda;

- Sağlık çalışanlarının hizmet içi eğitimler ile mobbing davranışı, bu davranışı etkileyen faktörler ve mobbing'e yaklaşım konusunda farkındalıklarının artırılması, 
- Sağlık kurumlarında sağlık ekibi üyeleri arasında, sağlık çalışanları ile yöneticiler arasında açık ve etkin bir iletişimin sürdürülmesi,

- Sağlık çalışanlarının başarısını ödüllendiren, gelişimine katkı veren performans değerlendirmelerini dikkate alan objektif değerlendirme kriterlerinin oluşturulması,

- Sağlık kurumlarında mobbing uygulama potansiyeli olan kişileri bu davranıştan caydırıcı ve mobbing mağduru olma riski taşıyan bireyleri ise koruyucu düzenlemelerin yapılması,

- Mobbing mağduru çalışanlara yönelik kurumsal yardım ve destek programları oluşturulması,

- Mobbing yaşantılarının belirlenmesi ve etkin şekilde ele alınmasına ilişkin kurumsal düzeyde stratejiler geliştirilmesi,

- Her bir sağlık meslek grubunda görülen mobbing yaşantısına yönelik analitik çalışmalar yapılması önerilmektedir.

\section{KAYNAKLAR}

Aydın, S. İ. (2008). İşyerinde yıldırma (mobbing) algısına ilişkin bir alan çalışması. Yüksek Lisans Tezi, Hacettepe Üniversitesi Sosyal Bilimler Enstitüsü, Ankara.

Bardakçı, E. (2014). Bir üniversite hastanesinde çalışan hemşirelerin yaşadığı mobbingin ruhsal sağlıklarına etkisi. Yüksek Lisans Tezi, Dokuz Eylül Üniversitesi Sağlık Bilimleri Enstitüsü, İzmir.

Bostan, Ö., Erbil, N. (2004). Ebe ve hemşirelik iş doyumu, benlik sayg1s1 ve etkileyen faktörler. Atatürk Üniversitesi Hemşirelik Yüksekokulu Dergisi, 7(3): 56-66.

Cengiz, R., Aytaç, K. Y., Servi, T., Yetiş, Ü. (2012). Futbol kulüplerinde yıldırma algısı ile iş doyumu düzeyleri arasındaki ilişkisi. Adlyaman Üniversitesi Sosyal Bilimler Enstitüsü Dergisi, 5(9): 6575.

Çakıl, E. (2011). Üniversite hastanesinde çalışan hemşire ve asistanlarda mobbingin işe gönülden adanma üzerine etkisi. Yüksek Lisans Tezi, Zonguldak Karaelmas Üniversitesi Sosyal Bilimler Enstitüsü, Zonguldak.

Devanport, N., Distler-Schwartz, R., Pursel-Elliott, G. (2003). Mobbing, Emosyonel Abuse in The American Workplace. Çeviren: O. C. Önertoy, 2. basım, Sistem Yayıncılık, İstanbul.

Dikmetaş, E., Top, M., Ergin, G. (2011). Asistan hekimlerin tükenmişlik ve mobbing düzeylerinin incelenmesi. Türk Psikiyatri Dergisi, 22(3): 137-149.
Dilman, T. (2007). Özel hastanelerde çalışan hemşirelerin duygusal tacize maruz kalma durumlarının belirlenmesi. Yüksek Lisans Tezi, Marmara Üniversitesi Sağlık Bilimleri Enstitüsü, İstanbul.

Dündar, T. (2010). Sağlık çalışanlarının yıldırmaya maruz kalmalarında hastane etik iklimi ile sosyo-demografik özelliklerinin rolü: Bolu ili hastanelerinde bir uygulama. Yüksek Lisans Tezi, Hacettepe Üniversitesi Sağlık Bilimleri Enstitüsü, Ankara.

Einarsen, S., Matthiesen, S. B., Skogstad, A. (1998). Bullying, burnout and well-being among assistant nurses. Journal of Occupational Health and Safety, 14(6): 563-568.

Ferrinho, P. ve ark. (2003). Patterns of perceptions of workplace violence in the Portuguese health care sector. Human Resources for Health, 1: 1-11.

Fışkın, G. (2011). Mobbing davranışı ve ana çocuk sağlığı merkezlerindeki sağlık çalışanlarına yönelik bir araştırma. Yüksek Lisans Tezi, İstanbul Üniversitesi Sağllk Bilimler Enstitüsü, İstanbul.

Gürkan, K. P. (2010). Şanlıurfa'da çalışan hemşire, ebe ve sağlık memurlarının psikolojik şiddete (mobbing) maruz kalma durumları ve ilişkili faktörler. Yüksek Lisans Tezi, Harran Üniversitesi Sağlık Bilimleri Enstitüsü, Şanlıurfa.

Gökçe, T, A. (2006). İşyerinde yıldırma: Özel ve resmi ilköğretim okulu öğretmen ve yöneticileri üzerinde yapılan bir araştırma. Doktora Tezi, Ankara Üniversitesi Eğitim Bilimleri Enstitüsü, Ankara.

Hoel, H., Cooper, C., Faragher, B. (2001). The experience of bullying in Great Britain: The impact of organizational status. Europen Journal of Work and Organizatioanl Pstchology, 10(4): 443-465.

Jackson, M., Ashley, D. (2005). Physical and psychological violence in Jamaica's Health Sector. Pan Am J Public Health, 18(2): 114-121.

Jelic, J. Z., Stoini, E., Bunikic, C. S. (2005). The effect of mobbing on medical staff performance. Acta Clin Croat, 44(4): 347-352.

Karcioğlu, F., Akbaş, S. (2010). İş yerinde psikolojik şiddet ve iş tatmini ilişkisi. Atatürk Üniversitesi İktisadi ve İdari Bilimler Dergisi, 24(3): 139-162.

Kocaoğlu, M. (2007). Mobbing (işyerinde psikolojik taciz, yıldırma) uygulamaları ve motivasyon arasındaki ilişkinin incelenmesine yönelik bir araştırma. Yüksek Lisans Tezi, Yıldız Teknik Üniversitesi Sosyal Bilimler Enstitüsü, İstanbul.

Köse, S., Uysal, Ş. (2010). Kamu personelinin yıldırma (mobbing) ve boyutları hakkındaki düşünceleri üzerine bir çalışma: Manisa Tarım İl Müdürlüğü örneği. Celal Bayar Üniversitesi Sosyal Bilimler Dergisi, 8(1): 261-276.

Kuzey, C. (2012). Impact of health care employees' job satisfaction on organizational performance support vector machine approach. European Journal of Economic and Political Studies, 5(1): 65-89. 
Leymann, H. (1990). Mobbing and psychological terror at workplaces. Violence and Victims, 5(2): 119-126.

Leymann, H. (1996). The content and development of mobbing at work. Europen Journal of Work and Organizational Phychology, 5(2): 165-184.

Okyay, N. (2009). Emniyet teşkilatına bağlı okullardan mezun olup çevik kuvvet şube müdürlüğ̈̈nde görev yapan polislerin psikolojik şiddet algıları, iş doyumu ve tükenmişlik düzeylerinin incelenmesi. Yüksek Lisans Tezi, Çukurova Üniversitesi Sosyal Bilimler Enstitüsü, Adana.

Oran-Başkaya, N. (1989). Job satisfaction of a group of academical staff in Marmara University. Yüksek Lisans Tezi, Marmara Üniversitesi, İstanbul.

Quine, L. (2001). Workplace bulluying in nurses. Journal of health psychology, 6(1): 73-84.

Özalp, F. (2013). Çalışma yaşamında mobbing ve iş tatmini arasındaki iliş̧i: Kamu kuruluşunda bir uygulama. Yüksek Lisans Tezi, Aydın Üniversitesi Sosyal Bilimler Enstitüsü, İstanbul.

Salin, D. (2003). Ways of explaining workplace bullying: A review of enabling, motivating and precipitating structures and process in the work environment. Human Relations, 56(10): 1213-1232.

Steinman, S. (2003). Workplace violence in the health sector, country case study, South Africa, http://www.icn.ch/SewWorkplace/ WPV HS_South Africa (22.11. 2012).

Şahin, B., Dündar, T. (2011). Sağlık sektöründe etik iklim ve yıldırma (mobbing) davranışları arasındaki ilişkinin incelenmesi. Ankara Üniversitesi Siyasal Bilgiler Fakültesi Dergisi, 66(1): 129-159.

Tetik, S. (2010). Mobbing kavramı: Birey ve örgütler açısından önemi. Karamanoğlu Mehmet Bey Üniversitesi Sosyal ve Ekonomik Araştırmalar Dergisi, 12(18): 81-89.

Tınaz, P. (2011). İsyerinde Psikolojik Taciz (Mobbing). 3. basım, Beta Basım Yayım, İstanbul.

Tigrel, Y. E., Kokalan, O. (2009). Academic mobbing in Turkey. International Journal of Social, Behavioral, Educational, Economic, Business and Industrial Engineering, 55: 963-971.

Topal, E. (2008). Hekim ve hemşirelerin iş doyum düzeyleri. Yüksek Lisans Tezi, Hacettepe Üniversitesi Sağlık Bilimleri Enstitüsü, Ankara.

Tözün, M., Çulhacı, A., Ünsal, A. (2008). The job saticfaction of physicians that working in primary health care in institutions in family medicine system (Eskişehir). TAF Prev Med Bull, 7(5): 377-384.
Tüfekçi, M. (2014). Acil Tıp uzmanlık öğrencilerinde mobbing algı düzeylerinin incelenmesi. Tlpta Uzmanlık Tezi, Mersin Üniversitesi Tıp Fakültesi Acil Tıp Anabilim Dalı, Mersin.

Üye, C. (2009). Hemşirelerin yöneticileri tarafindan mobbing davranışları ile karşılaşma durumlarının belirlenmesi. Yüksek Lisans Tezi, Haliç Üniversitesi Sağlık Bilimleri Enstitüsü, İstanbul.

Vega, G., Comer, D. (2005). Sticks and stones may break your bones but words can break your spirit: Bullying in the workplace. Journal of Business Ethics, 58(1): 101-109.

Vural-Özkan, G. (2011). İş yerinde yıldırma (mobbing) ve iş doyumu ilişkisi. Yayınlanmış Yüksek Lisans Tezi, Dokuz Eylül Üniversitesi Sosyal Bilimler Enstitüsü, İzmir.

Weiss, D. J., Dawis, R. W., England, G. W., Lofquist, L. H. (1967). Manual for the Minnesota Satisfaction Quesition Naire. Minnesota Studies, Washington.

Yapıcı, N. (2008). İş yerlerinde sistematik yıldırma (mobbing), algılanan nedenleri ve iş tatmini ile işten ayrılma niyeti üzerine etkisi: Antalya ili tarım sektöründe bir araştırma. Yüksek Lisans Tezi, Akdeniz Üniversitesi Sosyal Bilimler Enstitüsü, Antalya.

Yavuz, H. (2007). Çalışanlarda mobbing (psikolojik şiddet) algısını etkileyen faktörler. Yayınlanmış Yüksek Lisans Tezi, Süleyman Demirel Üniversitesi Sosyal Bilimler Enstitüsü, Isparta.

Yelboğa, A. (2007). Bireysel demografik değişkenlerin iş doyumu ile ilişkisinin finans sektöründe incelenmesi. Sosyal Bilimler Dergisi, 4(2): 1-18.

Yıldırım, A. (2007). Sağlık kuruluşlarında psikolojik şiddetin (mobbing) tanımı, boyutları ve önemi. V. Ulusal Sağlık Kuruluşları Yönetimi Kongresi Bilimsel Kitabl, Antalya, 93-95.

Yıldırım, A., Yıldırım, D. (2007). Mobbing in the workplace by peers and managers: Mobbing experienced by nurses working in healthcare facilities in Turkey and its effect on nurses. Journal of Clinical Nursing, 16(8): 1444-1453.

Yıldız, S., Yıldız, S. E., Erdağı, S. (2009). Sağlık çalışanlarının psikolojik yıldırma davranışının değerlendirilmesi. Hastane Yönetimi Dergisi, 13(1): 1-13.

Yıldız, G., Akbolat, M., Işık, O. (2011). Psikolojik taciz ve örgütsel bağımlılık: Sağlık çalışanları üzerine bir araştırma. Sosyal Bilimler Dergisi, 25(13): 113-141.

Zonp, Z. (2012). Psikiyatri kliniklerinde çalışan hemşirelerin mobbing algıları ve ilişkili faktörler. Yüksek Lisans Tezi, İstanbul Üniversitesi Sağlık Bilimleri Enstitüsü, İstanbul. 